\title{
Perceived Helicopter Parenting and Depression Among Korean University Students: The Mediating Effect of Assertiveness
}

\author{
Ga Yeon Kim ${ }^{1}$, Ju Hee Park ${ }^{2}$ \\ M. A., Department of Child \& Family Studies, Yonsei University, Seoul, Korea ${ }^{1}$ \\ Professor, Department of Child \& Family Studies, Yonsei University, Seoul, Korea ${ }^{2}$ \\ 헬리콥터 부모양육태도가 대학생의 우울에 미치는 영향: 주장성의 매개효과 \\ 김가연 ${ }^{1}$, 박주희 ${ }^{2}$ \\ 연세대학교 아동가족학과 석삼, 연세대학교 아동가족학과 교수 ${ }^{2}$
}

\begin{abstract}
Objectives: This study aimed to investigate the mediating effect of assertiveness in the relationship between perceived helicopter parenting and depression among university students.

Methods: The participants of this study were 609 students (272 males and 337 females) who were enrolled in 25 universities located in Seoul and Gyung-gi province in Korea. The research variables were measured using the Center for Epidemiological Studies-Depression Scale (CES-D), Helicopter Parenting Scale (HPS), and Rathus Assertiveness Schedule (RAS). In order to examine the general tendency of the study variables, descriptive statistics and Pearson's correlation coefficients were calculated. Path analysis was also used to examine the mediating model.

Results: The results of this study were as follows; First, the level of perceived helicopter parenting increased the level of depression and decreased that of assertiveness in students. In addition, students' level of assertiveness had a significant negative influence on their level of depression. Second, the level of assertiveness partially mediated the effect of perceived helicopter parenting on depression.

Conclusion: In conclusion, the higher the level of perceived helicopter parenting, the lower the level of students' assertiveness and, subsequently, the higher their level of depression. These results suggested that reducing the level of helicopter parenting and encouraging assertiveness among university students would play an important role in reducing their depression.
\end{abstract}

Keywords: helicopter parenting, assertiveness, depression, university students, emerging adulthood

\section{Introduction}

최근 대학 시기에 급증하는 심리적 부적응과 관련하여 대2병이 라는 신조어가 탄생하는 등 대학생의 정신건강 문제가 중요한 사회적 이슈로 대두되고 있다(SBS, 2017). 대학생 시기는 성인 기로의 이행기에 해당하는 발달적으로 중요한 시기로서 부모

Corresponding Author: Ju Hee Park, Professor, Department of Child \& Family Studies, Yonsei University, 50 Yonsei-ro, Seodaemun-gu, Seoul, Korea

E-mail: juheepark@yonsei.ac.kr
로부터의 심리적 독립, 성숙한 대인관계 형성, 진로와 취업 결정 등을 포함한 심리사회적 과업들로 특징지어지기 때문에(Roscoe \& Peterson, 1984; Zal, 1992) 대학생들은 이로 인한 부담감과 스 트레스를 경험하게 된다. 이에 대학 신입생 시기를 지나 본격적 인 대학생활을 시작하면서부터 우울, 불안, 대인예민성, 신체화 증상, 자살위기의 위험성이 증가하는 등 정신건강 문제가 증가

(C)The Korean Association of Child Studies

This is an Open Access article distributed under the terms of the Creative Commons Attribution Non-Commercial License (http:// creativecommons.org/licenses/by-nc/4.0) which permits unrestricted noncommercial use, distribution, and reproduction in any medium, provided the original work is properly cited. 
하는 것으로 꾸준히 보고되고 있다(Oh, 2018). 특히 한국대학교 육협의회에서 발표한 2018년 '대학생의 심리적 위기 현황과 실 태' 보고(Oh, 2018)에서는 대학생 약 2,600여명 중에서 43.2\%가 우울감을 경험하고 있는 것으로 나타나 상당수의 대학생들이 우울로 인해 어려움을 겪고 있음을 보여주고 있다.

우울은 슬픈 감정 상태의 가벼운 우울감에서부터 일상생 활에 지장을 주는 임상적 장애까지 그 양상이 다양하게 나타 난다. 일반적으로 우울은 슬프고 울적한 기분, 거의 모든 활 동에 있어서 흥미나 즐거움의 상실, 에너지와 집중력 저하, 활 동력 감소, 무가치감 등으로 인해 나타나는 저조한 기분이나 감정으로 정의된다. 대학생의 우울은 학업 성취도, 진로미결 정, 자살행동 등과 관련이 있다고 보고되고 있고(Ahn, $\mathrm{Kim}, \&$ Choi, 2015; DeRoma, Leach, \& Leverett, 2009; Kisch, Leino, \& Silverman, 2005; Walker \& Peterson, 2012), 이후 성인기에도 재 발되는 만성적 우울 징후로 이어질 가능성이 높다(Rao et al., 1995). 또한 대학 시기의 우울 경험은 성인 초기의 주요 발달 과업인 자아개념 강화, 진로 탐색 등(Roscoe \& Peterson, 1984; $\mathrm{Zal}, 1992)$ 과 관련한 선택과 결정을 방해함으로써 이후 인생에 도 부정적인 영향을 미칠 가능성이 높기 때문에 각별한 주의 가 필요하다. 따라서 대학생의 우울에 대해 개인의 문제가 아 닌 사회적 현상이자 문제로 접근하여 대학 차원에서 보다 적 극적인 관심과 대비가 필요한 상황이다.

선행연구에서 대학생의 우울에 영향을 미치는 것으로 밝 혀진 심리사회적 요인은 주로 개인의 성격, 인지, 정서 등 심리 적 특성과 가족환경, 대인관계, 학교 등 사회적 특성이었으며 (Bahk \& Min, 2018), 이전 발달 시기에 비해 부모와 가족이 미 치는 영향의 중요성은 상대적으로 주목받지 못했다. 이는 대 학생 시기가 부모나 가족으로부터 벗어나 활동의 맥락이 확대 되고 성인으로서 자녀 스스로 자율성과 독립성을 발달시켜 나 가는 시기로 기대되기 때문이다. 그러나 21세기에 들어 대학 생의 졸업, 취업, 결혼 등이 유예되고 부모로부터 독립이 늦어 지는 사회적 현상이 나타나면서 이들이 성인진입기(emerging adulthood)라는 특수한 발달적 시기에 해당된다고 제안된 바 있다(Arnett, 2000). 이러한 주장과 함께 주로 아동.청소년기에 대해 연구가 되어오던 과보호적이거나 과잉간섭적 양육태도가 대학생 자녀에게 미치는 영향에 대해 주목하기 시작하였고, 이 를 헬리콥터 부모양육태도(helicopter parenting)로 개념화하였 다(Somers \& Settle, 2010a, 2010b). 헬리콥터 부모양육태도란 부 모가 자녀의 삶에 높은 수준으로 개입하고 자율적인 문제해결 과 의사결정을 허용하지 않는 양육이 성인진입기 이후에도 여 전히 도움이 된다고 믿기 때문에 어린시절부터 시작된 이와 같
은 태도가 발달적으로 부적절하게 지속되고 있음을 의미한다 (LeMoyne \& Buchanan, 2011). 이는 독립성과 자율성의 성취가 이루어져야 할 대학생 자녀에 대한 부모의 태도가 아동기 때와 다름없이 보호, 간섭, 통제에 기반한 양육으로 나타나는 현상 을 반영한다(Padilla-Walker \& Nelson, 2012; Schiffrin et al., 2014). 이와 같은 헬리콥터 부모양육태도가 대학생의 우울을 야기 하는 요인으로 작용할 수 있는 근거는 이것이 자녀에게 부정적 사고의 발달을 야기할 수 있기 때문이다. 어린 시절부터 지속적 으로 부모의 과잉 간섭을 경험해온 대학생은 자신의 자율적이 고 주체적인 문제해결능력과 의사결정능력에 대한 확신을 가 지기 어렵고, 자율성을 인정하지 않는 부모에게 순종하지 않거 나 부모의 기준을 충족시키지 못할 경우 부모의 애정이 상실될 것을 염려할 수 있다. 따라서 부모의 도움 없이는 스스로 무엇 인가를 성취할 수 없다는 인식과 부모의 애정이 조건적이라는 인식을 바탕으로 우울을 겪게 될 가능성이 높다. 최근 몇몇 선 행연구에서는 헬리콥터 부모양육태도가 대학생의 우울에 영향 을 미친다고 보고하였는데(Hong \& Doh, 2018; J. Lee \& Kang, 2018; Schiffrin et al., 2014), 이는 우울에 취약한 사람들의 무의 식에 위치한 두 가지 본질적인 핵심신념으로 '무능함'과 '사랑 받을 수 없음'이라는 부정적 인지구조가 있다고 주장한 Beck (2011)의 인지적 관점과 관련지어 설명될 수 있다.

한편, 최근에는 헬리콥터 부모양육태도가 대학생 자녀의 우 울에 미치는 영향에 대한 연구를 보다 구체화하여 헬리콥터 부 모양육태도가 어떠한 과정을 통해 우울을 야기하게 되는지를 규명하기 위한 연구자들의 시도가 이루어지고 있다. 예를 들 어, 자기효능감(Reed, Duncan, Lucier-Greer, Fixelle, \& Ferraro, 2016), 역기능적 완벽주의(Hong \& Doh, 2018), 부모에 대한 친밀감과 부모의 진로기대 부담(J. Lee \& Kang, 2018) 등의 매 개경로를 조사한 연구들이 있는데, 특히 Kouros, Pruitt, Ekas, Kiriaki와 Sunderland (2017)는 헬리콥터 부모양육태도가 성인 진입기 자녀의 우울을 발생시킬 수 있는 잠재적 경로의 하나로 서 개인이 사회적인 상황에서 대처하기 위해 자신의 행동을 조 절하는 기술을 제안한 바 있다. 이는 부모가 자녀 스스로 문제 를 해결하고 의사 결정을 내리는 데에 과잉간섭함으로써 대학 시기 자녀가 새로운 사회적 환경에서 적응적으로 대처하고 조 절하는 기술의 레퍼토리를 발달시키고 이를 사용하며 연습하 는 것을 방해할 수 있고(Abaied \& Emond, 2013), 그 결과 자녀 들이 우울을 경험할 가능성이 높기 때문이다. 대학생 시기는 중 - 고등학생 때와는 달리 확장된 환경 내에서 보다 다양한 방 식으로 사람들과 관계를 맺으며 자신의 도구적 목적에 맞게 적 응력을 발달시키고 도전적인 과제를 수행해 나가야 하는 시기 
이기 때문에 사회적 대처와 조절 기술 중에서도 특히 주장성 (assertiveness)이 헬리콥터 부모양육 태도에 의해 발달이 저해되 었을 가능성이 높은 변인이며, 동시에 우울에 취약해질 가능성 을 높이는 매개변인으로써 그 경로를 살펴볼 가치가 있다.

구체적으로 주장성이란 타인과의 의사소통 과정에서 상대 방의 권리를 침해하거나 상대방을 불쾌하게 하지 않으면서도 자신의 권리나 욕구, 의견, 생각, 느낌 등 자신이 나타내고자 하 는 바를 상대방에게 명확히 알리는 것을 의미한다(Alberti \& Emmons, 2017). 이러한 주장성이 헬리콥터 부모양육태도와 우 울 간 관계를 매개하는 경로는 행동학적 관점에서 우울의 발 생 원인에 대해 이론화한 Lewinsohn의 모델에 근거하여 설명 할 수 있다. Sanchez와 Lewinsohn (1980)의 연구에 따르면, 주장 성을 포함한 개인의 사회적 기술이란 타인으로부터 긍정적 결 과를 유도하는 방식으로 행동할 수 있는 능력이기 때문에 주 장성이 부족하여 대인관계 상호작용에서 보상, 욕구 충족, 만 족감을 더 적게 얻어내는 사람이 우울을 겪을 가능성이 높다고 하였다. 즉, 대인관계 상호작용에서 발현되는 적절한 주장성은 더 향상된 자존감과 도구적 목표 달성과 매우 큰 연관성이 있 기 때문에(Delamater \& McNamara, 1986) 개인의 욕구 충족을 통해 우울을 예방하거나 완화시킬 가능성이 있는 것이다. 실제 선행연구에서도 일반적으로 주장성이 향상되면 우울 수준이 감소함을 보고(Segrin, 2000)하고 있는데, 주장성과 우울 간의 인과관계를 명확히 규명하기 위해 우울 환자들을 대상으로 진 행한 경험적 연구에서는 우울과 주장적 행동의 관계를 5 주 동 안 조사한 결과, 주장적 행동은 그 다음 날의 우울 수준을 예측 한 반면 우울 수준은 그 다음 날의 주장적 행동 수준을 예측하 지 않아 주장성이 우울의 예측변인이 됨을 증명하였다(Sanchez \& Lewinsohn, 1980). 따라서 본 연구에서는 Lewinsohn과 동료 들의 이론(Lewinsohn, Hoberman, Teri, \& Hautzinger, 1985)에 근 거하여 주장성이 우울의 발생 원인이 된다고 가정하였다. 한 편, 주장성과 우울 간의 관계를 살펴본 국내 연구들은 주장성 을 측정하기 위해 다양한 문화권에 적용하기에는 한계가 있 는 것으로 알려진 대학생 자기표현 척도(College Self-Expression Scale [CSES])를 사용하였다는 점에서 제한적이었다. 또한 보다 문화보편적이고 사회적 바람직성의 영향을 덜 받는 것으로 알 려진 라터스 주장성 척도(Rathus Assertiveness Schedule [RAS]) 를 사용한 연구의 경우 대학생의 주장성과 우울 간 영향 관계 를 입증하지 못하였기 때문에 추가 연구를 통해 주장성이 우울 에 영향을 미치는지 규명할 필요가 있다.

앞서 살펴본 주장들에 근거하여 주장성의 매개효과에 대한 가능성을 살펴보면 다음과 같다. 헬리콥터 양육 태도를 보이
는 부모는 자녀의 욕구보다 자녀에게 도움이 될 것이라는 추측 에 근거한 자신의 욕구가 우선적으로 작용하여 자신의 양육 방 식에 자녀가 순종하고 비주장적으로 행동할 것을 독려하게 될 가능성이 높고, 자녀는 부모의 의사결정과 문제해결 능력이 자 신의 능력보다 더 낫다는 인식에 의해서나 혹은 부모의 의견을 따르지 않거나 충족시키지 못할 경우 부모의 애정을 상실할 것 을 염려하여 자기주장을 억제하는 방식으로 사회적 기술을 발 달시켰을 수 있다. 따라서 헬리콥터 부모양육태도를 경험하는 자녀는 가정 밖 사회적 환경에서도 주장성의 부족으로 인해 사 회적 상황에 적절히 대처하지 못하게 되는데, 타인과의 상호작 용에서 자신이 원하는 긍정적 결과를 만들어내는 주장적 행동 을 하지 못함으로써 욕구 좌절이 누적되어 우울을 경험할 가능 성이 높다. 이는 우울에 취약한 사람이 지닌 핵심신념을 설명 한 Beck (2011)의 인지이론과 사회적으로 보상받은 행동은 강 화되고, 그렇지 못한 행동은 약화된다고 한 강화이론(Michael, 2004)에 의해서도 뒷받침될 수 있다. 이를 종합하면 이와 같이 헬리콥터 부모양육태도가 대학생의 우울에 미치는 영향을 주 장성이 매개할 가능성이 있음에도 불구하고 이러한 가설을 경 험적으로 규명한 연구는 없기 때문에 이를 확인할 필요가 있다.

따라서 본 연구에서는 성인진입기 자녀 중에서도 헬리콥터 부모양육태도가 가장 우세한 집단이라고 보고된 바 있는 대학 생(Nelson, Padilla-Walker, Christensen, Evans, \& Carroll, 2011) 을 대상으로 하여 헬리콥터 부모양육태도가 주장성을 매개로 이들의 우울에 미치는 영향을 살펴보고자 한다. 이 때, 대학생 의 성, 학년, 그리고 가족의 소득수준이 우울에 영향을 미치는 요인이라는 선행연구 결과(Costello, Mustillo, Erkanli, Keeler, \& Angold, 2003; Y. Lee, Park, \& Kim, 2017; Oh, 2018)에 근거하여 이를 통제변인으로 포함하여 분석하고자 한다. 본 연구의 결 과는 변화하는 현대 사회의 시대상을 반영하여 부모의 헬리콥 터 양육태도가 대학생의 우울에 미치는 영향을 규명함으로써 대학생 우울 발생의 다양한 원인을 세부적으로 파악하고, 특 히 주장성으로 대표되는 사회적 기술을 기반으로 보다 구체적 인 우울 예방 및 중재 방안을 고안하고 도입하기 위한 근거를 제공할 수 있을 것이다.

\section{연구문제 1}

대학생의 헬리콥터 부모양육태도와 주장성은 우울에 영향을 미치는가?

\section{연구문제 2}

대학생의 주장성은 헬리콥터 부모양육태도가 우울에 미치는 
영향을 매개하는가?

\section{Methods}

\section{연구대상}

본 연구는 2018년 9월에 서울과 경기 지역에 소재한 25개(서 울 16 개, 경기 9개) 4년제 대학에 재학 중인 대학생 609명을 대 상으로 자기보고식 설문을 실시하고 분석에 사용하였다. 609 명 중 남학생은 272명(44.7\%), 여학생은 337명(55.3\%)이었 고, 학년별 비율은 1학년이 $15.3 \%, 2,3$, 4학년은 각각 $27.6 \%$, $30.2 \%, 26.8 \%$ 로 비교적 유사하였다. 대상의 월평균 가족 총소 득은 250 만원 이하가 $9.9 \%, 251$ 만원 이상에서 450 만원 이하 가 $21.8 \%, 451$ 만원 이상에서 650 만원 이하가 $22.7 \%, 651$ 만원 이상에서 850 만원 이하가 $17.7 . \%, 851$ 만원 이상이 $21.8 \%$, 그 리고 무응답이 $6.1 \%$ 로 나타났다.

\section{연구도구}

\section{우울(depression) 척도}

대학생의 우울증상을 측정하기 위해 Radloff (1977)가 개발한 '역학연구센터 우울 척도(Center for Epidemiological StudiesDepression Scale [CES-D])'를 Chon, Choi와 Yang (2001)이 한국 판으로 번안하고 타당화한 도구를 사용하였다. 본 척도는 일 반인들을 대상으로 현재의 우울한 정서를 측정하기 위해 개발 된 자기보고식 척도로써 응답자로 하여금 우울한 기분, 무가 치감, 절망감, 식욕 상실, 수면 장애 등 지난 일주일 동안 경험 한 우울 증상을 평정하도록 되어 있고 총 20 개 문항으로 구성 되어 있다. 각 문항은 4점 Likert 척도를 사용하여 거의 경험하 지 않음(0점)에서 거의 매일 경험함(3점)으로 응답한다. 4,8 , 12,16 번 문항은 긍정적 정서를 나타내는 문항으로서 역채점 하여 총점을 산출한다. 총점의 범위는 0 점에서 60 점까지로 점 수가 높을수록 우울증상의 정도가 심함을 의미한다. 측정도구 의 신뢰도를 확인하기 위해 본 연구에서 산출한 내적합치도 계수 Cronbach's $\alpha$ 는 .90이었다.

\section{헬리콥터 부모양육태도(helicopter parenting) 척도}

대학생 자녀가 지각한 헬리콥터 부모양육태도를 측정하기 위
해서 LeMoyne과 Buchanan (2011)이 개발한 헬리콥터 부모역 할 척도(Helicopter Parenting Scale [HPS])를 한국어로 번안하여 타당화한 Kwon, Yoo와 Bingham (2016)의 척도를 Kang과 Lee (2017)가 수정한 문항을 사용하였다. 본 척도는 어린 시절부터 지금까지 성장하는 동안 청년 자녀가 경험한 부모의 관여, 의 사결정 과정 개입 등을 측정하기 위해 개발된 도구로 총 10 개 문항으로 구성되어 있다. 각 문항은 5점 Likert 척도를 사용하 여 전혀 그렇지 않다(1점)에서 매우 그렇다(5점)로 응답하게 되어 있다. 총점의 범위는 10 점에서 50 점까지로 점수가 높을 수록 부모가 자녀의 삶에 어린 시절부터 성인진입기에 도달한 현재까지 지속적으로 개입하고 자율적인 문제해결과 의사결 정을 허용하지 않는 정도가 강함을 의미한다. 본 연구에서 산 출한 내적합치도 계수 Cronbach's $\alpha$ 는 .79이었다.

\section{주장성(assertiveness) 척도}

대학생의 주장성을 측정하기 위해서 Kong과 Oh (2003)가 한 국어로 번안하여 타당화한 라터스 주장성 척도(RAS; Rathus, 1973)를 사용하였다. 본 척도는 다양한 사회적 상황에서의 주 장성을 측정하는 자기보고식 도구로 총 30 개 문항으로 구성 되어 있다. 각 문항은 5점 Likert 척도를 사용하여 전혀 그렇지 않다(1점)에서 매우 그렇다(5점)로 응답한다. 총점의 범위는 30 점에서 150 점까지로 점수가 높을수록 타인과의 의사소통 과정에서 자신의 권리나 욕구, 의견, 생각, 느낌 등 자신이 나 타내고자 하는 바를 상대방에게 적절히 표현하는 정도가 강함 을 의미한다. 본 연구에서 산출한 내적합치도 계수 Cronbach's $\alpha$ 는 .87이었다.

\section{가족 총소득(family income) 척도}

대학생의 가족 총소득을 측정하기 위해 통계청 국가통계포털 에서 추출한 전국가구 소득 5 분위별 가계소득 추이(전국 2 인 이상) 자료를 참고로 하여 최종적으로 월평균 가구소득 구간 을 250 만원 이하, 251 만원 이상에서 450 만원 이하, 451 만원 이 상에서 650 만원 이하, 651 만원 이상에서 850 만원 이하, 851 만 원 이상으로 분류한 척도를 사용하였다.

\section{연구절차}

본 연구의 자료 수집은 서울과 경기 지역에 소재한 25개(서울 16 개, 경기 9개) 4 년제 대학에 재학 중인 대학생을 대상으로 이 
Table 1

Means and Standard Deviations of Variables

\begin{tabular}{lccccccc}
\hline & & \multicolumn{2}{c}{ Total } & \multicolumn{2}{c}{ Men $(n=272)$} & \multicolumn{2}{c}{ Women $(n=337)$} \\
\cline { 2 - 8 } \multicolumn{1}{c}{ Variables } & Score range & $M$ & $S D$ & $M$ & $S D$ & $M$ & \multicolumn{1}{c}{$S D$} \\
\hline Depression & $0-60$ & 17.98 & 9.47 & 16.35 & 8.43 & 19.29 & 10.06 \\
Helicopter parenting & $10-50$ & 26.60 & 6.14 & 26.61 & 5.86 & 26.60 & 6.36 \\
Assertiveness & $30-150$ & 93.56 & 13.65 & 95.75 & 13.25 & 91.78 & 13.72 \\
\hline
\end{tabular}

Note. $N=609$.

Table 2

Correlations Among Variables

\begin{tabular}{|c|c|c|c|c|c|c|}
\hline Variables & 1 & 2 & 3 & 4 & 5 & 6 \\
\hline 1. Depression & - & & & & & \\
\hline 2. Helicopter parenting & $.16^{* *}$ & - & & & & \\
\hline 4. Sex & $.16^{* *}$ & -.00 & $-.15^{* *}$ & - & & \\
\hline 5. Grade & .02 & -.05 & $.11^{* *}$ & -.02 & - & \\
\hline
\end{tabular}

Note. $N=609$.

${ }^{* *} p<.01$.

루어졌다. 연구 대상은 편의표집 방법을 통해 표집되었고, 연 구자가 각 대학의 수업 시간에 직접 방문하거나 개별 접촉을 통해 섭외한 대학생들에게 연구에 대해 간략하게 소개한 후 참 여에 동의한 이들에게 질문지를 배부하거나, 연구자로부터 자 료 수집에 대한 훈련을 받은 대학생 혹은 대학원생인 연구보조 원들이 동일한 방식으로 질문지를 배부하여 조사가 이루어졌 다. 총 660 부의 질문지를 배부하고 625 부를 회수하여 회수율 은 $94.7 \%$ 였으며, 이 중 최소 1 개 이상의 척도에 응답하지 않거 나 모든 문항을 동일한 값으로 평정하는 등 불성실한 응답으 로 판단되어 분석이 불가능한 16 부의 질문지를 제외한 후 총 609부의 자료를 최종 분석에 사용하였다.

\section{자료분석}

본 연구의 가설을 입증하기 위해 수집된 자료는 SPSS 25.0 (IBM Co., Armonk, NY) 프로그램과 AMOS 25.0 (IBM Co., Armonk, NY) 프로그램을 사용하여 다음과 같은 방법으로 분 석을 진행하였다. 첫째, 주요 변인들의 기술적인 경향을 알아 보고자 각 측정 변인 별로 평균과 표준편차를 산출하고, 측정 변인들 간의 관련성을 확인하기 위하여 Pearson의 적률상관계 수를 산출하였다. 둘째, 연구 모형의 검증을 위하여 최대우도 법 추정(maximum likelihood estimation methods)을 적용한 경 로분석(path analysis)을 실시하여 본 연구모형의 적합성을 확 인한 후, 측정변인 간의 경로계수와 그 유의성을 확인하였다. 다음으로 헬리콥터 부모양육태도가 대학생의 우울에 미치는 영향에서 주장성의 매개효과가 통계적으로 유의한지 확인하 기 위해 부트스트랩(bootstrap) 방법을 적용하여 매개효과의 유의성을 검정하였다. 부트스트랩 절차를 바탕으로 본 연구의 원자료 $(N=609)$ 에서 무작위 표본추출된 5,000개의 표본으로 부터 간접 효과를 추정하였으며, 간접효과의 $95 \%$ 신뢰구간에 0 이 포함되지 않을 때, 통계적으로 유의한 것으로 판단하였다 (Shrout \& Bolger, 2002).

\section{Results}

\section{대학생의 우울, 헬리콥터 부모양육태도 및 주장성의 일반적 경향}

\section{측정 변인들의 평균과 표준편차}

각 변인의 일반적 경향을 알아보기 위해 기술통계 값을 산출 하였고, 그 결과는 Table 1 에 제시하였다. 연구 대상인 전체 대 학생의 평균 우울 수준은 17.98 점 $(S D=9.47)$ 이었고, 헬리콥터 
Table 3

Fit Indices for the Path Analysis Model

\begin{tabular}{ccccccccc}
\hline & $\chi^{2}$ & $d f$ & $p$ & $\chi^{2} / d f$ & NFI & TLI & CFI & RMSEA \\
\hline Model & 8.750 & 5 & .119 & 1.750 & .984 & .927 & .976 & .035 \\
\hline
\end{tabular}

Note. $d f=$ degrees of freedom; NFI = normed fit index; TLI = Tucker-Lewis index; CFI = comparative fit index; RMSEA = root mean square error of approximation.

Table 4

Path Coefficients for the Final Model

\begin{tabular}{|c|c|c|c|c|}
\hline Path & $\beta$ & $S E$ & C.R. & $p$ value \\
\hline Helicopter parenting $\rightarrow$ Assertiveness & -.190 & .089 & $-4.762^{* * *}$ & .000 \\
\hline Assertiveness $\rightarrow$ Depression & -.304 & .027 & $-7.919^{* * *}$ & .000 \\
\hline Helicopter parenting $\rightarrow$ Depression & .113 & .058 & $3.002^{* *}$ & .003 \\
\hline Sex $\rightarrow$ Depression & .108 & .712 & $2.896^{* *}$ & .004 \\
\hline Grade $\rightarrow$ Depression & .063 & .340 & 1.707 & .088 \\
\hline Family income $\rightarrow$ Depression & -.138 & .147 & $-3.705^{* * *}$ & .000 \\
\hline
\end{tabular}

Note. $N=609$.

${ }^{* *} p<.01 .{ }^{* * *} p<.001$.

부모양육태도는 26.60점 $(S D=6.14)$, 주장성은 93.56점 $(S D=$ 13.65)이었다.

\section{측정 변인들 간의 상관관계}

본 연구에서 사용된 측정변인들이 어떠한 관련성을 가지고 있 는지 알아보기 위해 Pearson의 적률상관계수를 산출하였고, 그 결과는 Table 2에 제시하였다. 헬리콥터 부모양육태도는 우울 과 유의한 정적 상관 $(r=.16, p<.01)$ 을 보인 반면, 주장성과는 유의한 부적 상관 $(r=-.19, p<.01)$ 을 보였다. 이는 대학생이 인 식한 부모의 헬리콥터 양육태도 수준이 높을수록 대학생의 주 장성이 낮아지고, 더 높은 수준의 우울을 보고한다는 것을 나 타낸다. 또한 주장성은 우울과 부적 상관관계 $(r=-.35, p<.01)$ 가 있었다. 이는 자신의 주장성을 낮게 인식하는 대학생이 우 울을 겪을 가능성이 더 높음을 의미한다.

\section{헬리콥터 부모양육태도가 대학생의 우울에 미치는 영향에 대한 주장성의 매개효과}

\section{경로모형 적합도 평가}

헬리콥터 부모양육태도가 대학생의 우울에 미치는 영향을 주 장성이 매개할 것이라고 가정한 연구모형을 경로분석을 통
해 검증하였다. 우선 경로모형의 적합도를 확인하였고, 그 결 과는 Table 3에 제시하였다. $\chi^{2}(5)=8.750$ ( $\left.p=.119\right)$ 으로 $\chi^{2}$ 통 계량이 유의하지 않게 나와 모형의 적합도 수준이 적절한 것 으로 나타났다. 다음으로 $\chi^{2} / d f$ 는 1.750 로 나타났는데, 2 미만 으로 나타나 좋은 적합도로 판단할 수 있다. 다른 적합도 지수 들인 NFI, TLI, CFI가 모두 .90을 넘어 양호한 수준이었으며, $\mathrm{RMSEA}$ 는 .05 이하로 나타나 모형의 적합도가 좋은 편으로 확 인되었다.

\section{경로계수 유의성 검증}

다음으로 헬리콥터 부모양육태도와 주장성 및 우울 간의 관계 를 살펴보기 위해 연구 모형의 경로계수를 산출하였고, 그 결 과는 Table 4에 제시하였다. 헬리콥터 부모양육태도는 주장성 에 부적 영향을 주는 것으로 나타나 $(\beta=-.190, p<.001)$, 대학 생이 지각한 부모의 헬리콥터 양육태도 수준이 높을수록 대학 생의 주장성 수준이 낮아지는 것을 확인할 수 있었다. 다음으 로, 주장성은 우울에 부적 영향을 주는 것으로 나타났는데 $(\beta=$ -.304, $p$ <.001), 이는 대학생의 주장성이 낮을수록 우울 수준 은 높아짐을 의미한다. 그리고 헬리콥터 부모양육태도는 대학 생의 우울에 정적 영향을 주는 것으로 확인되어 $(\beta=.113, p<$ $.01)$, 부모의 헬리콥터 양육태도 수준을 높게 인식할수록 대학 생이 우울을 더 많이 경험하게 됨을 알 수 있었다. 
Table 5

Direct, Indirect, and Total Effects for the Final Model

\begin{tabular}{lccc}
\hline \multicolumn{1}{c}{ Path } & Direct effects & Indirect effects & Total effects \\
\hline Helicopter parenting $\rightarrow$ Assertiveness & $-.190^{* * *}$ & - & $-.190^{* * *}$ \\
Assertiveness $\rightarrow$ Depression & $-.304^{* * *}$ & - & $-.304^{* * *}$ \\
Helicopter parenting $\rightarrow$ Depression & $.113^{* *}$ & $.058^{* * *}$ & $.171^{* *}$ \\
\hline
\end{tabular}

Note. $N=609$.

${ }^{* *} p<.01 .{ }^{* * *} p<.001$.

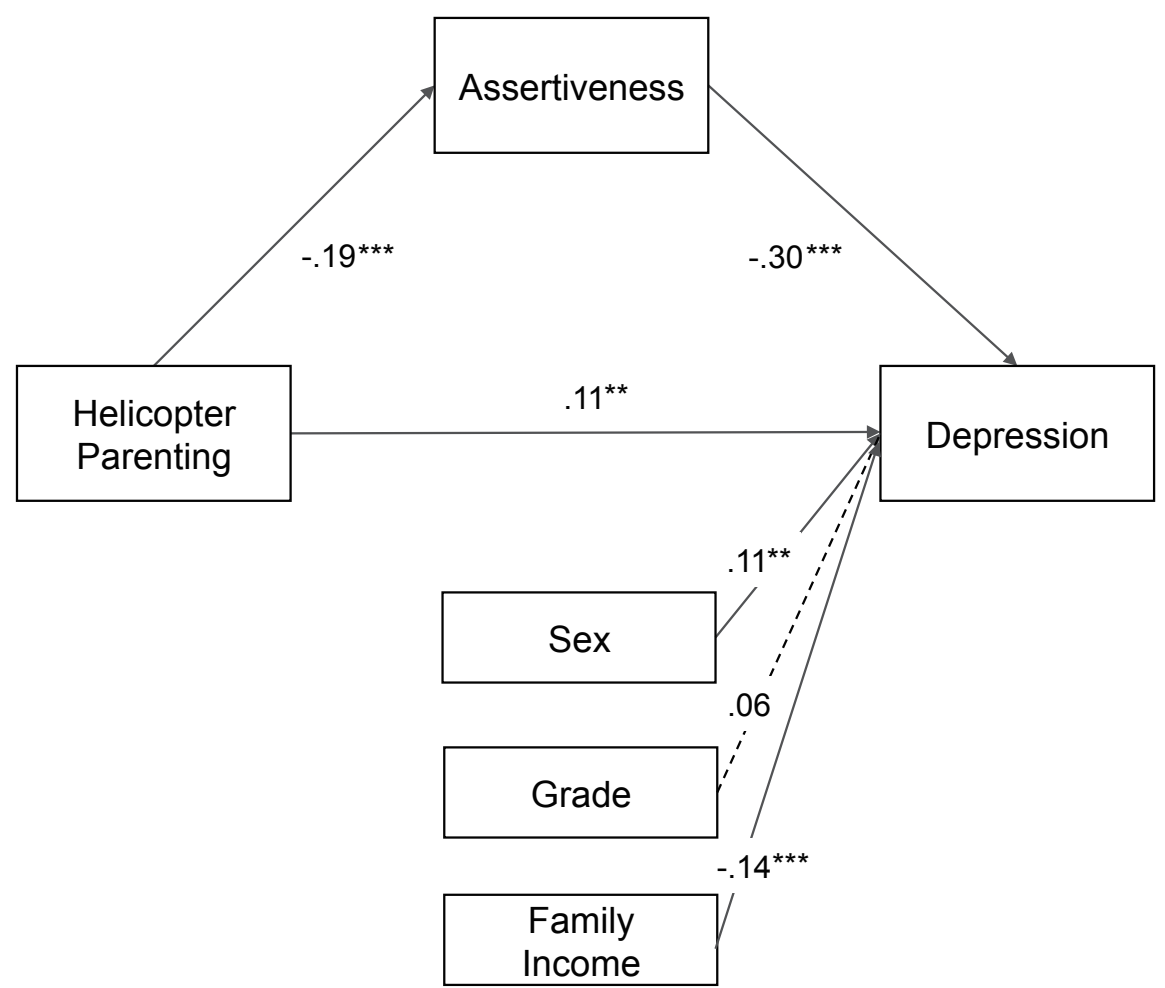

Figure 1. The effect of perceived helicopter parenting and assertiveness on depression.

${ }^{* *} p<.01 .{ }^{* * *} p<.001$.

\section{연구모형 검증}

주장성의 매개효과가 통계적으로 유의한 수준인지 검증하기 위해 부트스트랩(bootstrap) 방법을 적용하여 분석하였고, 그 결과는 Table 5에 제시하였다. 헬리콥터 부모양육태도에서 우 울에 이르는 직접효과는 통계적으로 유의한 것으로 나타났으 며 $(\beta=.113, p<.01)$, 헬리콥터 부모양육태도가 주장성을 매개 로 우울에 이르는 간접효과 또한 유의하게 나타났다 $\beta=.058$, $p<.001)$. 즉, 헬리콥터 부모양육태도, 주장성 및 우울 간의 관 계에서 직접효과와 간접효과를 모두 포함하는 부분매개 모형 이 본 연구모형을 설명하기에 적절한 것을 확인할 수 있었다.
이를 종합하면, 대학생이 부모의 헬리콥터 양육태도를 더 많 이 경험할수록 우울이 높아질 뿐만 아니라 주장성이 낮아지게 되는데, 낮아진 주장성은 다시 우울을 높이는 요인으로 작용 하게 된다는 것을 알 수 있었다.

\section{최종 경로모형}

이와 같은 분석 결과들을 종합하여 본 연구에서 확인된 헬리 콥터 부모양육태도와 주장성 및 우울 간의 부분매개 관계를 반영한 최종모형의 경로계수는 Figure 1과 같다. 


\section{Discussion}

본 연구는 성인진입기에 해당하는 대학생들이 경험하는 헬리 콥터 부모양육태도와 우울 간의 관계에서 주장성의 매개효과 를 살펴보기 위해 실시되었으며, 주요 결과들을 중심으로 논 의하면 다음과 같다.

첫째, 대학생이 지각한 부모의 헬리콥터 양육태도는 대학 생의 우울에 정적인 영향을 미치는 것으로 나타났다. 이와 같 은 연구 결과는 Beck (2011)의 우울에 대한 인지적 취약성 모 델에 근거하여 헬리콥터 부모양육태도가 부모의 과잉간섭으 로 인해 자녀에게 스스로 무능하거나 사랑받을 수 없다는 부 정적 사고를 발달시킴으로써 대학생 자녀의 우울을 야기하는 요인으로 작용할 수 있다고 한 본 연구의 주장을 뒷받침하며, 헬리콥터 부모양육태도의 우울에 대한 영향력을 보고한 선 행 연구들과 일치하는 결과이다(Darlow, Norvilitis, \& Schuetze, 2017; Hong \& Doh, 2018; J. Lee \& Kang, 2018; Schiffrin et al., 2014). 또한 이러한 결과는 헬리콥터 부모양육 태도가 자녀의 자율성 욕구를 좌절시키는 사회 환경이기 때문에 심리적 건 강을 해칠 수 있다고 한 Reed 등(2016)의 주장과 일치하는 결 과이며, 기본적 심리 욕구인 자율성이 충족되어야 개인이 보 다 나은 심리적 건강을 경험하고 발달에 필요한 주요한 성장 과정을 겪어 나갈 수 있다고 한 자기결정성 이론(Ryan \& Deci, 2017)을 지지하는 결과이기도 하다. 이와 같은 연구결과에 기 초해 보면, 대학생의 우울 예방을 위해서는 그들이 보다 긍정 적인 신념을 바탕으로 스스로 자율성과 통제력을 발휘할 수 있도록 대학생에 대한 직접적인 상담 개입과 함께 부모가 양 육태도를 바꿀 필요가 있음을 알 수 있다.

둘째, 주장성은 대학생의 우울에 부적인 영향을 미치는 것 으로 나타났다. 즉, 높은 수준의 주장성은 우울 수준을 낮추는 요인으로 작용하는 반면, 주장성의 수준이 낮을수록 우울 증 상을 경험할 가능성이 높음을 의미한다. 이러한 연구 결과는 주장성이 우울의 강력한 예측변인이 된다는 것을 확인한 선행 연구 결과와 일치한다(Ball, Otto, Pollack, \& Rosenbaum, 1994; Sanchez \& Lewinsohn, 1980). 또한 주장성이 부족하여 대인관 계 상호작용에서 보상, 욕구 충족, 만족감을 더 적게 얻어내는 사람이 우울을 겪을 가능성이 높다고 한 Sanchez와 Lewinsohn (1980)의 주장과도 부합하는 결과이다. 이는 주장성이 더 향상된 자존감과 도구적 목표 달성과 관련이 있기 때문에 (Delamater \& McNamara, 1986), 주장성이 낮으면 대인관계 상 호작용에서 자신의 욕구가 반영되지 못함으로 인해 불만족감 이 누적되어 결국 우울을 경험할 가능성이 높아진다는 사실
을 뒷받침해준다. 또한 주장성은 개인의 자존감, 자신감, 대인 관계, 개인적 성취 등을 향상시킨다(Delamater \& McNamara, 1986)고 알려져 있기 때문에 이러한 연구 결과에서 착안하여 헬리콥터 부모양육태도로 인한 대학생의 우울 예방과 감소를 위해 주장성 훈련(assertion training)의 적용을 고려해볼 수 있 을 것이다.

셋째, 본 연구에서 헬리콥터 부모양육태도가 주장성을 통 해 우울에 영향을 미치는 매개경로를 검증한 결과, 대학생이 지각한 헬리콥터 부모양육태도과 우울증상의 관계에서 주장 성이 부분매개 역할을 하는 것으로 나타났다. 이는 부모가 자 녀의 어린 시절부터 대학생이 된 현재까지 지속적으로 과잉 간섭적 양육인 헬리콥터 양육태도를 보일 때, 자녀의 주장성 이 실제로 감소하며 이로 인해 우울을 경험할 가능성이 높다 는 본 연구의 가설과 일치한다. 즉, 헬리콥터 양육태도를 보이 는 부모는 자신의 양육방식에 자녀가 따르기를 독려하기 때문 에 이러한 양육방식을 경험한 대학생은 부모의 의사결정과 문 제해결 능력이 자신의 능력 보다 더 낫다고 인식하거나 혹은 부모의 의견을 따르지 않거나 충족시키지 못할 경우 관심과 애정을 상실할 것을 염려하여 자기주장을 억제하고 부모의 의 견을 따르는 상호작용 방식을 발달시키게 되고, 이로 인해 가 정을 벗어난 환경에서도 대인관계 상호작용에서 자신이 원하 는 긍정적 결과를 만들어내는 주장성을 발휘하지 못함으로써 욕구 좌절이 누적되어 우울을 경험하게 될 가능성이 높아짐을 알 수 있다. 이는 무능함과 사랑받을 수 없음이 우울에 취약한 사람이 지닌 핵심신념이라고 주장한 Beck (2011)의 인지이론 과 사회적으로 보상받은 행동은 강화되고, 그렇지 못한 행동 은 약화된다고 한 강화이론(Michael, 2004)에 의해서 뒷받침될 수 있다.

이에 본 연구결과에서 확인한 매개경로를 토대로 대학생의 우울 수준을 낮추기 위해 개인적 차원, 가족차원, 사회적 차원 에서 몇 가지 방안을 제안하고자 한다. 우선 개인적 차원에서 헬리콥터 부모양육태도로 인한 대학생의 우울 예방과 감소를 위해 주장성 훈련(assertion training)의 적용을 고려해볼 수 있 다. 이는 주장적 행동을 직접적으로 형성하기 위한 임상적 개 입(Rathus, 1973)으로 우울증 치료를 위한 사회기술훈련의 일 환으로 진행되는 치료기법이다(Kramer, Bernstein, \& Phares, 2009). 일반적으로 주장성은 개인의 자존감, 자신감, 대인관 계, 개인적 성취 등을 향상시킨다고 알려져 있고(Delamater \& $\mathrm{McNamara}, 1986)$, 스트레스와 관련된 사고와 감정을 사회적 상황에 적절하게 주장적으로 표현하는 것은 반복적으로 떠오 르는 부정적 생각의 빈도를 감소시킴으로써 적응을 촉진시킨 
다고 하였다(Pennebaker, 1993). 따라서 주장성 증진 훈련은 부 모의 헬리콥터 양육태도로 인한 부정적 영향이 누적된 대학생 의 우울 증상 개선뿐만 아니라 삶의 만족도 향상에 기여할 것 으로 기대된다.

헬리콥터 양육태도로 인해 우울을 경험하는 대학생의 부모 에게 직접 개입하여 양육태도를 바꾸려는 시도는 현실적으로 실행하는 데에 제한이 있다. 부모 스스로 문제의 심각성을 깨 닫지 못하거나 자신의 태도를 수정해야 할 필요성에 동의하지 않을 수 있고, 상담 현장에 대학생의 부모가 참여하기에는 여 러 가지 현실적인 제약이 있을 수 있기 때문이다. 따라서 부모 대상 개입과 인식의 변화는 현실적으로 어려울 수 있으나, 본 연구결과를 통해 대학생 자녀의 주장성을 강화시키는 것이 더 중요함을 알 수 있다. 즉, 보다 실질적인 접근 방안으로써 대학 생의 주장성 증진 훈련은 부모보다 상담 현장에 대한 심리적, 물리적 접근이 용이한 당사자에게 개입함으로써 헬리콥터 부 모양육태도로 인해 유발된 대학생의 우울을 감소시킬 수 있다 는 점에서 주목할 만하다. 이러한 개입은 대학상담센터 등과 같은 기관에서 심리적 도움을 필요로 하는 대학생들을 대상으 로 진행될 수 있기 때문에 효과적인 방안이 될 수 있다.

특히 대학생의 주장성을 보다 효과적으로 증진시키기 위해 서 부모의 헬리콥터 양육태도로 인해 형성된 대학생의 왜곡된 인지체계를 개선하고, 이러한 역기능적 사고로부터 기인한 비 주장적 행동을 개선시키는 통합적 개입을 고려해볼 수 있다. 이는 헬리콥터 부모양육태도가 우울을 유발하는 직접적인 경 로에서뿐만 아니라 주장성을 통해 우울에 영향을 미치는 매개 경로에서도 자녀의 부정적 핵심신념이 작용했을 가능성이 있 기 때문이다. 이러한 맥락에서 대학생의 인지적 측면과 행동 적 측면에 대해 동시에 개입할 수 있는 인지행동치료(cognitive behavior therapy)는 우울 예방과 치료를 위한 가장 효과적인 방 안이 될 수 있다. 예를 들어, 주장성 훈련에 인지적 접근을 접 목하여 주장행동과 관련된 비합리적 생각을 찾아 이를 합리적 생각으로 대체하는 인지적 주장훈련, 주장행동과 관련된 불안 을 줄이는 정서적 주장훈련, 그리고 주장행동의 요소를 습득 하는 행동적 주장 훈련을 모두 포함하여 단기간 시행하는 집 중적 주장성 훈련(S.-H. Kim, 2002)의 실시를 고려해볼 수 있 다. 이러한 접근은 비주장적 행동의 원인을 행동적, 인지적, 정 서적 원인으로 분류한 Rakos (1991)의 제안에 근거한 것으로 주장성을 증진시키기 위한 체계적인 시도로써 대학생들에게 도 효과가 있을 것으로 예상된다.

다음으로 가족적 차원에서 헬리콥터 부모양육태도가 자녀 의 성장 시기 동안 지속되어 누적된 결과로 인해 대학생이 낮
은 주장성을 보이고 우울을 경험하기 때문에, 아동.청소년기 자녀를 둔 부모들을 대상으로 한 예방적 개입은 향후 우울로 이어질 수 있는 경로를 미리 차단하거나 예방하는 효과를 나 타낼 수도 있을 것으로 기대된다. 부모가 자녀에게 발달적으 로 적절한 독립성을 격려하고 스스로 의사결정을 하고 적극적 으로 문제를 해결할 수 있도록 자신감을 길러주는 자율성 지 지적 양육태도(Kouros et al., 2017)를 보일 경우, 자녀는 더 높 은 자기효능감과 더 낮은 우울감을 나타냈다(Reed et al., 2016). 따라서 자녀의 발달단계에 맞춰 부적절한 과잉간섭은 지양하 고 자율성은 지지할 수 있도록 양육태도를 조정하는 데 도움 을 주는 부모 개입방안의 마련을 고려해볼 수 있다. 예를 들어, 자기결정성 이론(Ryan \& Deci, 2017)에 근거하여 자녀의 기본 심리 욕구인 자율성, 관계성, 유능성의 충족을 지지해 줄 수 있 는 양육행동을 증진시키는 프로그램(Jeong \& Shin, 2011)은 효 과적인 부모교육 방안이 될 수 있다. 이러한 유형의 부모교육 프로그램에 대한 지속적 연구와 개발은 부모의 긍정적 양육행 동 증진과 함께 자율성을 포함한 자녀의 심리적 만족도 향상 에 도움이 될 것으로 기대된다.

추가적으로 사회적 차원에서 부모의 헬리콥터 양육태도가 대학생을 포함한 성인진입기 자녀의 정신건강과 발달적 위험 에 미치는 부정적 영향에 대한 사회적 인식 제고가 필요하다. 헬리콥터 양육태도를 보이는 부모는 단지 부모의 관점에서 애 정으로 간주되는 동기에 기반하여 지원을 제공하기 때문에 그 것이 자녀에게 미치는 영향에 대해 긍정적일 것이라고 왜곡 할 가능성이 있다. 그러나 그것이 의도와는 달리 자율성을 침 해하거나 자존감에 대한 위협으로 지각되면, 실질적 도움과는 별개로 자녀의 정신 건강 측면에서 부정적 결과를 가져올 수 있다는 사실을 명확히 인지할 필요가 있다. 특히, 국가적으로 평균 수명이 연장되며 백세시대로 접어들고 있기 때문에 성인 진입기를 시작으로 한 성인 자녀와 부모 간 관계가 아동.청소 년기보다 긴 50년 이상의 오랜 기간 동안 유지될 가능성이 높 다. 그런데 성인도입기 이후의 자녀에 대한 부모 역할에 대해 서는 사회적 인식이나 정보가 거의 없는 실정이다.

따라서 변화하는 가족생활주기에 기반하여 성인진입기 자 녀의 건강한 발달을 독려하는 유능한 부모역할에 대한 재개념 화가 필요하며, 우선 부모가 자녀와 심리적으로 분리되는 것 이 중요하고 자녀를 통해 자신의 삶의 의미를 찾는 대신 부모 스스로의 인생을 재설계하도록 해야 한다. 이는 자녀의 건강 한 발달뿐만 아니라 부모 자신이 건강한 중.장년 이후의 삶을 영위하기 위해서도 필수적인데, 자녀에게 과잉간섭하는 부모 는 자녀에 대한 지나친 헌신으로 인한 에너지 소진과 개인의 
삶을 포기함으로써 삶의 만족도 저하라는 부정적 결과를 경험 할 수 있기 때문이다(Schiffrin et al., 2014). 특히 우리나라는 전 통적으로 가족주의 문화를 가지고 있고(Ryu, 2007), 유교 문화 는 자녀에 대한 부모의 헌신을 당연하고 바람직한 것으로 인 식하도록 하여 부모-자녀관계에 있어 강한 동일체감을 형성 하였기 때문에(J. Kim, 2010), 부모들이 자녀의 자율성 지지를 덜 하고 과잉간섭적 행동을 더 많이 할 가능성이 높으므로 각 별한 주의가 필요하다.

한편, 본 연구에서 통제변인으로 투입한 대학생의 성, 학년, 가족 총소득 중에서는 성과 가족 총소득이 우울에 유의미한 영향을 미치는 것으로 나타났다. 우선 대학생의 성은 우울 수 준에 영향을 미쳤으며, 이는 여자 대학생이 남자 대학생보다 더 높은 수준의 우울을 경험한다고 보고한 선행연구의 결과와 일치한다(Costello et al., 2003; Oh, 2018). 또한, 대학생의 가족 총소득이 높을수록 낮은 수준의 우울 수준을 보고하였는데, 이는 대학생의 가족 총소득이 낮으면 경제적 스트레스로 인해 우울이 증가한다는 선행연구(Y. Lee et al., 2017)와 일치하는 결 과이다. 이는 대학생이 단순 피부양자의 입장이기보다는 성인 진입기 자녀로서 가족의 낮은 소득 수준에 대해 공동 책임감 을 느끼고 경제적 스트레스를 받을 수 있기 때문이다. 따라서 대학생의 우울 예방 및 치료에 있어서 성별에 따른 차별적 개 입과 경제적 스트레스를 경감시키는 개입을 접목시킬 필요가 있고, 추가적으로 사회적 차원에서 대학 등록금 인하나 저소 득층 가정 대학생을 대상으로 한 지원금과 장학금 조성 등의 지속적인 노력이 더욱 필요할 것이다.

마지막으로 본 연구가 갖는 제한점을 밝히며 후속 연구에 대한 제언을 제시하면 다음과 같다. 첫째, 본 연구에서는 각 변 인들을 한 시점에 측정한 횡단자료를 사용하였기 때문에 측 정 변인들 간의 인과관계를 명확히 파악하기에는 한계가 있 다. 연구 결과에서 헬리콥터 부모양육태도가 대학생의 주장성 에 영향을 미치는 것으로 나타났지만, 어린시절부터 자녀의 주장성이 부족하여 부모가 대신 문제를 해결해주고 결정을 내 려주는 과잉간섭적 양육태도를 보이기 시작했고, 그것이 자녀 가 성인진입기에 도달한 현재까지 이어졌을 가능성도 있다. 이러한 한계를 보완하기 위하여 어린 시절부터 현재까지 이어 지는 부모양육태도를 회고식으로 측정하는 도구(LeMoyne \& Buchanan, 2011)를 사용하였지만, 추후 연구에서는 종단적 연 구 모형을 도입하여 헬리콥터 부모양육태도와 자녀의 주장성, 그리고 정신 건강 간의 인과관계를 보다 명확히 검증할 필요 가 있다.

둘째, 본 연구에서 사용한 측정 도구와 관련된 한계점이다.
본 연구에서는 대학생이 지각한 부모의 헬리콥터 양육태도를 측정하기 위해 헬리콥터 부모역할 척도(LeMoyne \& Buchanan, 2011)를 사용하였다. 실제 상호작용의 모습보다 개인이 인지 한 상호작용의 양상이 심리적 적응에 중요하게 작용한다는 연 구 결과(Sabatelli \& Anderson, 1991)에 근거하여 본 연구에서는 이와 같은 자기보고식 척도를 사용하였다. 그럼에도 불구하고 이 도구는 어린 시절부터 현재까지 경험한 과잉간섭과 관련된 부모의 가치관과 태도에 대한 대학생의 인식을 측정하는 도구 이기 때문에 부모의 실제 양육행동을 정확히 반영하지 못했을 가능성을 배제할 수 없다. 또한 가족 관련 변인을 측정함에 있 어 다양한 가족 구성원들의 관점을 종합해야 한다는 제안도 있다(Sabatelli \& Bartle, 1995). 따라서 추후 연구에서는 부모가 지각하는 헬리콥터 양육태도를 함께 측정하여 부모와 자녀가 느끼는 헬리콥터 양육태도 수준의 차이를 살펴봄으로써 자녀 에 대한 부모의 적절한 개입 수준에 대한 정보를 얻을 수 있을 것이다.

셋째, 본 연구에서는 헬리콥터 부모양육태도가 대학생의 우울에 미치는 영향과 주장성의 매개효과를 설명하며 근거 이 론 중 하나로 무능함과 사랑받을 수 없음이라는 두 가지 부정 적 핵심신념에 기반한 인지체계 이론(Beck, 2011)을 사용하였 다. 그런데 본 연구에서는 헬리콥터 부모양육태도로 인해 대 학생의 우울이 유발되는 과정을 매개하는 변인으로서 자녀의 주장적 행동을 측정하고, 인지적 측면은 가설적으로만 규명하 였을 뿐 직접적으로 측정하지 않았다. 따라서 추후 연구에서 는 헬리콥터 부모양육태도를 경험하는 대학생의 우울을 유발 하는 매개변인으로 부정적 핵심신념을 측정하여 이러한 가설 을 보다 구체적으로 확인할 필요가 있다.

이러한 제한점에도 불구하고 본 연구 결과는 다음과 같은 의의를 가지고 있다. 첫째, 대학생이 인식한 헬리콥터 부모양 육태도와 주장성이 우울에 미치는 영향에 대해 알아봄으로써 대학생의 우울을 유발하는 예측요인에 대한 심층적인 이해를 도모하였다. 특히 부모 관련 변인 중에서도 최근 주목 받고 있 는 헬리콥터 부모양육태도의 우울에 대한 영향력을 살펴봄으 로써 현재 우리 사회가 처한 상황과 성인진입기라는 발달적 특수성을 반영하여 대학생 우울의 발생 원인을 확인할 수 있 었다. 이를 통해 대학생의 우울을 낮추기 위한 방안으로써 성 인진입기 이후 자녀를 둔 부모의 올바른 역할에 대한 사회적 인식을 제고하고 부모-자녀 간 관계를 재설정하는 것의 중요 성을 확인하였다는 점에서 의의가 있다.

둘째, 본 연구에서 주장성의 부분매개효과를 확인함으로써 대학생이 지각한 부모의 헬리콥터 양육태도가 우울에 영향을 
미치는 구체적 과정을 규명하였을 뿐만 아니라 이 경로에 개 입하는 매개변인에 대한 개념적 확대를 이루었다. 특히 주장 성은 이미 임상 현장에서 우울 증상을 개선하는 데 효과가 있 음이 규명된 요인으로 해외에서는 이와 관련한 치료적 프로그 램에 대한 경험적 연구가 많이 축적되어 있고, 헬리콥터 부모 양육태도로 인해 우울을 경험하는 당사자에게 직접 개입할 수 있기 때문에 매개변인으로써 임상적 함의가 크다. 따라서 대 학생의 우울 완화를 위한 실천적 개입 방안과 관련하여 헬리 콥터 부모양육태도로 인해 우울을 경험하는 대학생들을 대상 으로 부정적 핵심신념을 수정하는 인지적 상담 기법과 주장성 증진 훈련을 통합적으로 실시하는 인지행동치료 차원에서의 개입이 필요함을 확인할 수 있었다.

\section{Notes}

This article is a part of the first author's master's thesis submitted in 2018, and was presented as a poster at the 2019 Spring Joint Conference of UN SDG4.2.

\section{Conflict of Interest}

No potential conflict of interest relevant to this article was reported.

\section{References}

\section{In English}

Abaied, J. L., \& Emond, C. (2013). Parent psychological control and responses to interpersonal stress in emerging adulthood: Moderating effects of behavioral inhibition and behavioral activation. Emerging Adulthood, 1(4), 258-270. doi: $10.1177 / 2167696813485737$

Alberti, R. E., \& Emmons, M. L. (2017). Your perfect right: Assertiveness and equality in your life and relationships (10th ed.). Oakland, CA: New Harbinger Publications.

Arnett, J. J. (2000). Emerging adulthood: A theory of development from the late teens through the twenties. American Psychologist, 55(5), 469-480. doi:10.1037/0003-066X.55.5.469

Ball, S. G., Otto, M. W., Pollack, M. H., \& Rosenbaum, J. F. (1994). Predicting prospective episodes of depression in patients with panic disorder: A longitudinal study. Journal of Consulting and Clinical Psychology, 62(2), 359-365. doi:10.1037/0022-006X.62.2.359

Beck, J. S. (2011). Cognitive behavior therapy: Basics and beyond (2nd ed.). New York: The Guilford Press.

Costello, E. J., Mustillo, S., Erkanli, A., Keeler, G., \& Angold, A. (2003). Prevalence and development of psychiatric disorders in childhood and adolescence. Archives of General Psychiatry, 60(8), 837-844. doi:10.1001/archpsyc.60.8.837

Darlow, V., Norvilitis, J. M., \& Schuetze, P. (2017). The relationship between helicopter parenting and adjustment to college. Journal of Child and Family Studies, 26(8), 22912298. doi:10.1007/s10826-017-0751-3

Delamater, R. J., \& McNamara, J. R. (1986). The social impact of assertiveness: Research findings and clinical implications. Behavior Modification, 10(2), 139-158. doi:10.1177/01454455860102001

DeRoma, V. M., Leach, J. B., \& Leverett, J. P. (2009). The relationship between depression and college academic performance. College Students Journal, 43(2), 325-334.

Kisch, J., Leino, E. V., \& Silverman, M. M. (2005). Aspects of suicidal behavior, depression, and treatment in college students: Results from the spring 2000 national college health assessment survey. Suicide and Life-Threatening Behavior, 35(1), 3-13.

Kouros, C. D., Pruitt, M. M., Ekas, N. V., Kiriaki, R., \& Sunderland, M. (2017). Helicopter parenting, autonomy support, and college students' mental health and wellbeing: The moderating role of sex and ethnicity. Journal of Child and Family Studies, 26(3), 939-949. doi:10.1007/ s10826-016-0614-3

Kramer, G. P., Bernstein, D. A., \& Phares, V. (2009). Introduction to clinical psychology (7th ed.). Upper Saddle River, NJ: Pearson Prentice-Hall.

Lee, J., \& Kang, S. (2018). Perceived helicopter parenting and Korean emerging adults' psychological adjustment: The mediational role of parent-child affection and pressure from parental career expectations. Journal of Child and Family Studies, 27(11), 3672-3686.

LeMoyne, T., \& Buchanan, T. (2011). Does "hovering" matter? Helicopter parenting and its effect on well-being. Sociological Spectrum, 31(4), 399-418. doi:10.1080/02732173.2011.574 038

Lewinsohn, P. M., Hoberman, H., Teri, L., \& Hautzinger, M. (1985). An integrative theory of depression. In S. Reiss \& R. R. Bootzin (Eds.), Theoretical issues in behavior therapy (pp. 331-359). Orlando, FL: Academic Press.

Michael, J. L. (2004). Concepts and principles of behavior analysis (2nd ed.). Kalamazoo, MI: Western Michigan University, Association for Behavior Analysis International.

Nelson, L. J., Padilla-Walker, L. M., Christensen, K. J., Evans, C. A., 
\& Carroll, J. S. (2011). Parenting in emerging adulthood: An examination of parenting clusters and correlates. Journal of Youth and Adolescence, 40(6), 730-743. doi:10.1007/ s10964-010-9584-8

Padilla-Walker, L. M., \& Nelson, L. J. (2012). Black hawk down?: Establishing helicopter parenting as a distinct construct from other forms of parental control during emerging adulthood. Journal of Adolescence, 35(5), 1177-1190. doi:10.1016/j.adolescence.2012.03.007

Pennebaker, J. W. (1993). Putting stress into words: Health, linguistic, and therapeutic implications. Behaviour Research and Therapy, 31(6), 539-548. doi:10.1016/0005-7967(93)90105-4

Rakos, R. F. (1991). Assertive behavior: Theory, research and training. New York: Routledge.

Rao, U., Ryan, N. D., Birmaher, B., Dahl, R. E., Williamson, D. E., Kaufman, J., Rao, R., \& Nelson, B. (1995). Unipolar depression in adolescents: Clinical outcome in adulthood. Journal of the American Academy of Child \& Adolescent Psychiatry, 34(5), 566-578. doi:10.1097/00004583199505000-00009

Rathus, S. A. (1973). A 30-item schedule for assessing assertive behavior. Behavior Therapy, 4(3), 398-406. doi:10.1016/ S0005-7894(73)80120-0

Reed, K., Duncan, J. M., Lucier-Greer, M., Fixelle, C., \& Ferraro, A. J. (2016). Helicopter parenting and emerging adult self-efficacy: Implications for mental and physical health. Journal of Child and Family Studies, 25(10), 3136-3149. doi:10.1007/s10826-016-0466-x

Roscoe, B., \& Peterson, K. L. (1984). Older adolescents: A selfreport of engagement in developmental tasks. Adolescence, 19(74), 391-396.

Ryan, R. M., \& Deci, E. L. (2017). Self-determination theory: Basic psychological needs in motivation, development, and wellness. New York: The Guilford Press.

Sabatelli, R. M., \& Anderson, S. A. (1991). Family system dynamics, peer relationships, and adolescents' psychological adjustment. Family Relations, 40(4), 363-369. doi:10.2307/584891

Sabatelli, R. M., \& Bartle, S. E. (1995). Survey approaches to the assessment of family functioning: Conceptual, operational, and analytical issues. Journal of Marriage and the Family, 57(4), 1025-1039. doi:10.2307/353420

Sanchez, V., \& Lewinsohn, P. M. (1980). Assertive behavior and depression. Journal of Consulting and Clinical Psychology, 48(1), 119-120. doi:10.1037/0022-006X.48.1.119

Schiffrin, H. H., Liss, M., Miles-McLean, H., Geary, K. A., Erchull, M. J., \& Tashner, T. (2014). Helping or hovering? The effects of helicopter parenting on college students' wellbeing. Journal of Child and Family Studies, 23(3), 548-557. doi:10.1007/s10826-013-9716-3
Segrin, C. (2000). Social skills deficits associated with depression. Clinical Psychology Review, 20(3), 379-403. doi:10.1016/ S0272-7358(98)00104-4

Shrout, P. E., \& Bolger, N. (2002). Mediation in experimental and nonexperimental studies: New procedures and recommendations. Psychological Methods, 7(4), 422-445. doi:10.1037/1082-989X.7.4.422

Somers, P., \& Settle, J. (2010a). The helicopter parent: International arrivals and departures. College and University, 86(2), 2-9.

Somers, P., \& Settle, J. (2010b). The helicopter parent: Research toward a typology. College and University, 86(1), 18-24, 2627.

Walker, J. V., \& Peterson, G. W. (2012). Career thoughts, indecision, and depression: Implications for mental health assessment in career counseling. Journal of Career Assessment, 20(4), 497506.

Zal, H. M. (1992). The sandwich generation: Caught between growing children and aging parents. New York: Insight Books/Plenum Press.

\section{In Korean}

Ahn, S. Y., Kim, J. H., \& Choi, B. Y. (2015). Meta-analysis on variables related to suicidal ideation among college students. The Korean Journal of School Psychology, 12(3), 385-405.

Bahk, W., \& Min, K. (2018). Textbook of depressive disorders. Seoul: Sigma Press.

Chon, K. K., Choi, S.-C., \& Yang, B.-C. (2001). Integrated adaption of CES-D in Korea. Korean Journal of Health Psychology, 6(1), 59-76.

Hong, M.-H., \& Doh, H.-S. (2018). Effects of helicopter parenting on depression in female emerging adults: Examining the mediating role of adaptive and maladaptive perfectionism. Korean Journal of Child Studies, 39(6), 143158. doi:10.5723/kjcs.2018.39.6.143

Jeong, G.-Y., \& Shin, H.-C. (2011). Development and validation of the parent education program based on self-determination theory. The Korean Journal of Counseling and Psychotherapy, 23(3), 603-634.

Kang, S., \& Lee, J. (2017). Validation of the Korean version of the helicopter parenting scale for an expanded age range of young adults. Journal of Family Relations, 22(2), 3-25. doi:10.21321/ jfr.22.2.3

Kim, J. (2010). The effect of parental overprotection on college adjustment, anxiety, and depression: Focusing on Korean cultural aspects and gender differences (Master's thesis). Retrieved from http://www.riss.kr/link?id=T11991556

Kim, S.-H. (2002). The effects of intensive assertiveness training on the assertive behavior, thinking and emotion. The Korea 
Journal of Counseling, 3(1), 81-96.

Kong, J.-E. (2003). A study on the effect of self-assertiveness on adolescents' tobacco and alcohol use behavior (Master's thesis). Retrieved from http://www.riss.kr/link?id=T8616874

Lee, Y., Park, S. Y., \& Kim, M. J. (2017). Economic stress, depression, suicidal ideation, resilience, and social support in college students. Journal of Korean Academy of Psychiatric and Mental Health Nursing, 26(2), 151-162. doi:10.12934/ jkpmhn.2017.26.2.151

Oh, H. (2018, March). Daehaksaengui simnijeok wigi hyeonhwanggwa siltae [대학생의 심리적 위기 현황과 실태]. Paper presented at the 57th University Education Policy Forum of Korean Council for University Education, Seoul, Korea. Retrieved from http://www.kcue.or.kr

Ryu, J.-H. (2007). A study on the parent-child relation, famlism, and hyo. Korean Journal of Parent Education, 4(2), 81-94.
SBS. (2017, April 3). "Ije mwol haeya haji?”... 'Dae2byeong'e sidallineun cheongnyeondeul [“이제 뭘 해야 하지?”...'대2병' 에 시달리는 청년들]. SBS News. Retrieved from http:// news.sbs.co.kr/news/endPage.do?news_id=N1004125625

$\begin{array}{ll}\text { Ga Yeon Kim } & \text { https://orcid.org/0000-0003-0553-7635 } \\ \text { Ju Hee Park } & \text { http://orcid.org/0000-0003-3031-0272 }\end{array}$

Received June 30, 2019

Revision received July 29, 2019

Accepted July 31, 2019 